\title{
Transcatheter aortic valve implantation in patients with severe aortic valve stenosis and large aortic annulus, using the self-expanding 31-mm Medtronic CoreValve prosthesis: First clinical experience
}

\author{
Freek Nijhoff, MD, ${ }^{\mathrm{a}}$ Pierfrancesco Agostoni, MD, PhD, ${ }^{\mathrm{a}}$ Hafid Amrane, MD, ${ }^{\mathrm{b}}$ Azeem Latib, MD, ${ }^{\mathrm{c}}$ \\ Luca Testa, MD, PhD, ${ }^{\mathrm{d}}$ Jacopo A. Oreglia, MD, ${ }^{\mathrm{e}}$ Federico De Marco, MD, ${ }^{\mathrm{e}}$ Mariam Samim, MD, ${ }^{\mathrm{a}}$ \\ Francesco Bedogni, MD, ${ }^{\mathrm{d}}$ Francesco Maisano, $\mathrm{MD},{ }^{\mathrm{c}}$ Giuseppe Bruschi, MD, FESC, ${ }^{\mathrm{e}}$ \\ Antonio Colombo, MD, ${ }^{c}$ Ad J. Van Boven, MD, PhD, ${ }^{b}$ and Pieter R. Stella, MD, $\mathrm{PhD}^{\mathrm{a}}$
}

\begin{abstract}
Objectives: With the introduction of the 31-mm Medtronic CoreValve prosthesis, patients with large aortic annulus have become eligible for transcatheter aortic valve implantation. The aim of this study was to evaluate the feasibility, efficacy, and safety of transcatheter aortic valve implantation using the 31-mm Medtronic CoreValve in patients with severe aortic valve stenosis and large aortic annulus.
\end{abstract}

\begin{abstract}
Methods: Five institutions in the Netherlands and Italy participated in a retrospective multicenter registry. Clinical, procedural, and imaging data of patients treated with the 31-mm Medtronic CoreValve were retrospectively collected in accordance with the Valve Academic Research Consortium-2 criteria.
\end{abstract}

\begin{abstract}
Results: Between August 2011 and November 2012, 47 patients (44 men, mean age $77.6 \pm 8.9$ years) received the 31-mm Medtronic CoreValve prosthesis for severe aortic stenosis. Device success (correct positioning of a single valve with intended performance and no all-cause 30-day mortality) was achieved in 31 patients $(66.0 \%)$. Reasons for failing the device success criteria were significant prosthetic aortic regurgitation in 3 patients $(6.4 \%)$, second valve implantation in 10 patients $(21.2 \%)$ ( 8 cases of malpositioning with high-grade aortic regurgitation, 1 acute valve dislocation, and 1 delayed valve dislocation), 1 of whom died intrahospital, and in-hospital mortality in a further 3 patients $(6.4 \%)$. Peak and mean transaortic gradients decreased significantly $(P<.01)$. The rate of new pacemaker implantations was $41.7 \%$.
\end{abstract}

Conclusions: In this retrospective multicenter registry, transcatheter treatment of severe aortic valve stenosis with the 31-mm Medtronic CoreValve seemed to be challenging, even in experienced hands. If the prosthesis is properly implanted, it offers adequate valve hemodynamics and proper functioning. (J Thorac Cardiovasc Surg 2014;148:492-9)

\section{Supplemental material is available online.}

Transcatheter aortic valve implantation (TAVI) is a rapidly evolving treatment modality for patients with symptomatic

\footnotetext{
From the Department of Cardiology, ${ }^{\text {a }}$ University Medical Center Utrecht, Utrecht, The Netherlands; Medisch Centrum Leeuwarden, ${ }^{\mathrm{b}}$ Afdeling Hartcatheterisatie, Leeuwarden, The Netherlands; San Raffaele Scientific Institute, ${ }^{\mathrm{c}}$ Milan, Italy; Istituto Clinico Sant'Ambrogio, ${ }^{\mathrm{d}}$ Milan, Italy; and Ospedale Niguarda Ca' Granda, Milan, Italy.

Disclosures: A. Latib is a consultant for Direct Flow and an advisory board member for Medtronic, F. Bedogni is a medical proctor for Medtronic, G. Bruschi is a consultant for Medtronic, and P.R. Stella is a medical proctor for Edwards Lifesciences. All other authors have nothing to disclose with regard to commercial support.

Drs Nijhoff and Agostoni equally contributed to this article.

Received for publication July 10, 2013; revisions received Sept 19, 2013; accepted for publication Sept 30, 2013; available ahead of print Nov 21, 2013.

Address for reprints: Pieter R. Stella, MD, PhD, Department of Cardiology, University Medical Center Utrecht, Heidelberglaan 100, Room E.04.210, 3584 CX, Utrecht, The Netherlands (E-mail: p.stella@umcutrecht.nl).

0022-5223/\$36.00

Copyright (c) 2014 by The American Association for Thoracic Surgery

http://dx.doi.org/10.1016/j.jtcvs.2013.09.059
}

severe aortic valve stenosis (AS), significantly improving survival and quality of life. ${ }^{1,2}$ Current application of TAVI is confined to patients with prohibitive or high risk for surgical aortic valve replacement (SAVR), ${ }^{3}$ although trials involving intermediate-risk patients are ongoing. ${ }^{4}$ Until recently, another constraint to the practice of TAVI was the limited range of prosthesis sizes. Patients with severe AS and large aortic annulus (diameter $>27 \mathrm{~mm}$ ), otherwise suitable for TAVI, had to be denied transcatheter treatment because no adequately sized prostheses were available. In response to the clinical need for a larger valve prosthesis, the self-expanding 31-mm Medtronic CoreValve (MCV31; Medtronic Inc., Minneapolis, Minn) has been developed. With the introduction of this device, patients with an aortic annulus dimension up to $29 \mathrm{~mm}$ in diameter have become eligible for TAVI. However, the clinical use of this larger prosthesis may enhance the procedural challenges. As only the basal inflow portion of the stent frame has a 31$\mathrm{mm}$ profile, there is little margin for proper valve placement, rendering valve positioning more decisive to achieve a good implantation result. Furthermore, the bulky stent frame may increase the risk of interference with mitral valve 


\section{Abbreviations and Acronyms \\ $\mathrm{AR}=$ Aortic regurgitation \\ AS $=$ Aortic valve stenosis \\ $\mathrm{CE}=$ Conformité Européenne \\ MSCT = Multislice computer tomography \\ NYHA $=$ New York Heart Association \\ SAVR = Surgical aortic valve replacement \\ TAVI $=$ Transcatheter aortic valve implantation \\ TEE $=$ transesophageal echocardiography \\ TTE $=$ transthoracic echocardiography \\ VARC-2 $=$ Valve Academic Research \\ Consortium-2}

function ${ }^{6}$ and damage to the cardiac conduction system during prosthesis deployment. ${ }^{7}$ So far, no studies regarding clinical experiences with the MCV31 have been published. The aim of this study was to investigate the safety, efficacy, and in-hospital outcomes of TAVI using the MCV31 device.

\section{METHODS}

For a comprehensive description of the study methodology, please refer to the online supplementary methods section.

\section{Study Design}

This study is an observational, retrospective, multicenter, single-arm registry. All patients who underwent TAVI for severe aortic valve disease using the MCV31device were retrospectively identified. Patients selected for TAVI had been considered unsuitable for SAVR by consensus of a cardiologist and a cardiac surgeon, because of a high predicted operative mortality risk (logistic EuroSCORE >15) or the presence of absolute contraindications for SAVR (eg, porcelain aorta). Further details on patient selection have been published previously. ${ }^{3}$ Patient data were retrospectively collected and documented in a registry. All patients gave informed consent for the procedure and because of the retrospective nature of the study design, ethics committee approval was waived.

\section{Device and Implantation Procedure}

The MCV31 device received CE (Conformité Européenne) approval in August 2011 for transfemoral, transaxillary, and direct aortic implantation, and has roughly the same design characteristics as its smaller 26-mm and 29 -mm predecessors. ${ }^{8}$ It is only the stent frame inflow portion of the MCV31 that is larger compared with the $29-\mathrm{mm}$ prosthesis, giving rise to a pronounced tapering of the inflow portion (Figure 1). Therefore, correct placement, high enough to allow proper apposition of the enlarged inflow part to the native aortic valve, is more critical than with the smaller sizes. The TAVI procedures were performed via the transfemoral, transaxillary, or direct aortic approach according to the choice of the operators, with standard access techniques, ${ }^{9,10}$ under general anesthesia or conscious sedation. The implantation result (valvular function and location) was assessed by angiography and echocardiography (either transthoracic echocardiography [TTE], transesophageal echocardiography [TEE] or intracardiac echocardiography).

\section{End Point Definitions}

In-hospital complications were registered in concordance with the recently published Valve Academic Research Consortium-2 (VARC-2) consensus document. ${ }^{11}$ Device success was defined accordingly as the proper implantation of the first valve prosthesis used, with intended performance of the prosthetic heart valve (peak aortic flow velocity $<3 \mathrm{~m} / \mathrm{s}$ and no moderate or severe aortic regurgitation $[\mathrm{AR}]$ ) and no procedural mortality (30-day all-cause mortality).

\section{Statistical Analysis}

All data were analyzed using IBM SPSS Statistics software version 20 (IBM Corp., Armonk, NY). Results for continuous variables are presented as means \pm standard deviation or medians [interquartile range], as considered appropriate. Categorical variables are reported as counts and percentages. The comparison of continuous variables was done using the Student $t$ test for unpaired measures or paired $t$ test for repeated measures or their nonparametric equivalents, the Mann-Whitney $U$ test, and the Wilcoxon signed ranks test, where appropriate. Categorical variables were analyzed using the $\chi^{2}$ or Fisher exact test.

\section{RESULTS}

Between the CE approval of the MCV31in August 2011 and November 2012, 440 patients underwent TAVI at 5 participating institutions in the Netherlands and Italy. All centers were well experienced in CoreValve implantations (23, 26, and $29 \mathrm{~mm})$ when the MCV31 was introduced. Fifty-four patients $(12.3 \%)$ received the MCV31 device. Seven patients were excluded from the study because of off-label use of the prosthesis for pure severe AR without AS, leaving 47 patients for further analysis. Most of the patients were male $(93.6 \%)$; the mean age was $77.6 \pm 8.9$ years, ranging from 48 to 90 years. Further baseline characteristics are listed in Table 1. The mean aortic annulus diameter (average annulus diameter, as derived from the maximum and minimum diameters) was $26.4 \pm 2.7 \mathrm{~mm}$ on TEE and $27.3 \pm 1.6 \mathrm{~mm}$ on multislice computer tomography (MSCT). Overall left ventricular function was depressed; 24 patients (44.5\%) exhibited a left ventricular ejection fraction less than $40 \%$. Preprocedural imaging findings are summarized in Table 2.

\section{Procedural Results}

Most patients underwent TAVI through a transfemoral approach (36 patients), 6 patients were treated via direct aortic access, and 5 patients underwent a transaxillary procedure. Acute procedural success (such as that shown in Figure $2, A)$ was achieved in 36 patients $(76.6 \%)$. One intraprocedural death occurred, caused by ascending aortic dissection resulting in cardiac tamponade during a transfemoral procedure. In 1 patient, the valve prosthesis acutely embolized to the ascending aorta, which was adequately managed by snare catheter fixation and relocation of the prosthesis in the ascending aorta, followed by implantation of a second valve prosthesis in series (Figure 2, $C$ and $D$ ).

Twenty-two patients $(46.8 \%)$ demonstrated significant paravalvular AR (grade 2 or higher) immediately after valve deployment. In 9 of these patients (19.1\%), significant paravalvular AR occurred as a consequence of incorrect valve placement, exclusively concerning too low implantations (Figure 2, B). Seven of these patients required implantation 


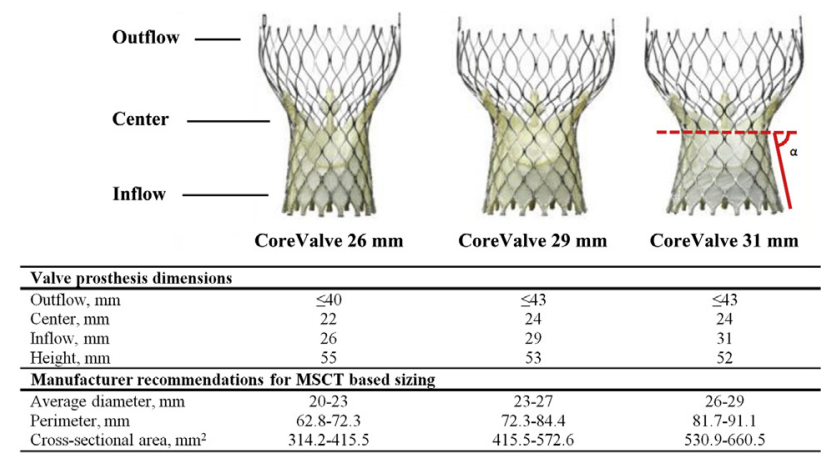

FIGURE 1. Medtronic CoreValve range of prostheses. The CoreValve third-generation range of prostheses with corresponding stent frame dimensions and manufacturer recommendations for MSCT-based sizing. MSCT, Multislice computer tomography.

of a second valve prosthesis (TAV-in-TAV) in the same setting, 1 patient received TAV-in-TAV implantation during a second procedure, and 1 patient was treated with snare catheter repositioning only (correct annular placement was achieved by gently pulling the prosthesis upwards,

TABLE 1. Baseline characteristics

\begin{tabular}{|c|c|}
\hline & Number $(\%)(N=47)^{2}$ \\
\hline Age, y & $77.6 \pm 8.9$ \\
\hline Female & $3(6.4)$ \\
\hline Body mass index, $\mathrm{kg} / \mathrm{m}^{2}$ & $26.7 \pm 4.7$ \\
\hline Length, cm & $173.0 \pm 7.5$ \\
\hline Weight, $\mathrm{kg}$ & $80.1 \pm 14.0$ \\
\hline Body surface area, $\mathrm{m}^{2} \dagger$ & $1.95 \pm 0.19$ \\
\hline Diabetes mellitus & $12(25.5)$ \\
\hline Hypertension & $30(63.8)$ \\
\hline Dyslipidemia & $23(48.9)$ \\
\hline COPD & $20(42.6)$ \\
\hline Chronic renal disease & $20(42.6)$ \\
\hline Glomerular filtration rate, $\mathrm{mL} / \mathrm{min} \ddagger$ & $58.6 \pm 21.4$ \\
\hline Cerebrovascular disease & $13(27.7)$ \\
\hline Peripheral artery disease & $18(38.3)$ \\
\hline Coronary artery disease & $30(63.8)$ \\
\hline Previous myocardial infarction & $11(23.4)$ \\
\hline Previous PCI & $21(44.7)$ \\
\hline Previous CABG & $9(19.1)$ \\
\hline Atrial fibrillation & $16(34.0)$ \\
\hline Previous pacemaker implantation & $11(23.4)$ \\
\hline \multicolumn{2}{|l|}{ Heart rhythm } \\
\hline Sinus rhythm & $35(74.5)$ \\
\hline Atrial fibrillation & 7 (14.9) \\
\hline Pacemaker rhythm & $5(10.6)$ \\
\hline NYHA functional class $\geq$ III & $37(78.7)$ \\
\hline Logistic EuroSCORE $\S(\%)$ & $24.7 \pm 23.3$ \\
\hline Prohibitive high risk for surgery $\|$ & $32(68.1)$ \\
\hline
\end{tabular}

COPD, Chronic obstructive pulmonary disease; $P C I$, percutaneous coronary intervention; $C A B G$, coronary artery bypass grafting; NYHA, New York Heart Association; EuroSCORE, European System for Cardiac Operative Risk Evaluation. *Results are given as the number (\%) except where indicated otherwise. $\dagger$ Calculated using the Mosteller formula. $\ddagger$ Estimated with the Modification of Diet in Renal Disease formula. §Operative risk as assessed by the EuroSCORE I. ||Defined as a logistic EuroSCORE $\geq 15.0 \%$.
TABLE 2. Preprocedural imaging

\begin{tabular}{lc}
\hline & $\mathbf{N}=\mathbf{4 7}$ \\
\hline Left ventricular ejection fraction $(\%)$ & $43.8 \pm 14.7$ \\
Left ventricular ejection fraction $<40 \%, \mathrm{n}(\%)$ & $19(40.4)$ \\
Peak aortic transvalvular pressure gradient $(\mathrm{mm} \mathrm{Hg})$ & $68.5 \pm 23.8$ \\
Mean aortic transvalvular pressure gradient $(\mathrm{mm} \mathrm{Hg})$ & $40.1 \pm 15.9$ \\
Aortic valve orifice area $\left(\mathrm{cm}^{2}\right)$ & $0.69 \pm 0.19$ \\
Aortic valve regurgitation grade 2 or higher, $\mathrm{n}(\%)$ & $13(27.7)$ \\
Mitral valve regurgitation grade 2 or higher & $11(23.4)$ \\
Systolic pulmonary artery pressure $(\mathrm{mm} \mathrm{Hg})$ & $40.4 \pm 10.9$ \\
Pulmonary artery hypertension (sPAP $\geq 60 \mathrm{~mm} \mathrm{Hg})$, & $4(8.5)$ \\
$\quad \mathrm{n}(\%)$ & $26.4 \pm 2.7$ \\
Aortic annulus diameter on TEE (mm) & $27.3 \pm 1.6$ \\
Aortic annulus average diameter on MSCT (mm)* & (range 25.5-30.5) \\
& $12.2 \pm 4.7$ \\
\hline Percentage of oversizing $\dagger$ & sPA, Systolic pulmonary arterial pressure; TEE, transesophageal echocardiography; \\
MSCT, multislice computer tomography. $*$ Average diameter calculated using the for- \\
mula (maximum diameter + minimum diameter)/2. $\dagger$ As calculated by the formula \\
(prosthesis diameter - average diameter on MSCT)/prosthesis diameter.
\end{tabular}

although moderate paravalvular AR persisted). In another 12 patients $(25.5 \%)$, significant paravalvular AR was successfully addressed by postdilatation, because prosthesis underexpansion was the underlying cause. In the remaining patient, grade $2 \mathrm{AR}$ did not improve after postdilatation and was accepted, considering the risk of additional postdilatation. An overview of the procedural variables is given in Table 3.

\section{Echocardiographic Results}

All patients underwent TTE before discharge (Table 4), except for the patient who died during the procedure. Peak and mean aortic transvalvular pressure gradients decreased from $68.5 \pm 23.8 \mathrm{~mm} \mathrm{Hg}$ and $40.1 \pm 15.9 \mathrm{~mm}$ $\mathrm{Hg}$ at baseline to $18.0 \pm 6.3 \mathrm{~mm} \mathrm{Hg}$ and $9.9 \pm 3.7 \mathrm{~mm}$ Hg after TAVI, respectively (both $P<.001$ ). Predischarge echocardiography showed AR in 32 patients $(71.7 \%)$ : mild in 25 patients $(54.3 \%)$, moderate in 6 patients $(13.0 \%)$, and severe in 1 patient $(2.2 \%)$. The origin of postprocedural AR was predominantly paravalvular (29 of 32 cases) and less often transvalvular or mixed. The degree of mitral valve regurgitation (MR) decreased in 8 patients $(17.4 \%)$, remained unchanged in 27 patients $(57.4 \%)$, worsened in 7 patients $(15.2 \%)$, and was inadequately assessed in the remaining patients. Worsening of the degree of MR was not related to too low implantations that required TAV-in-TAV implantation. The change in the distribution of MR severity before and after TAVI was not significant $(P=.64)$, the proportion of patients with important MR (grade 2 or higher) remained the same.

\section{In-Hospital Outcome}

There were 4 in-hospital deaths ( $8.5 \%$ ), including the case of aortic dissection described earlier. One patient, with 


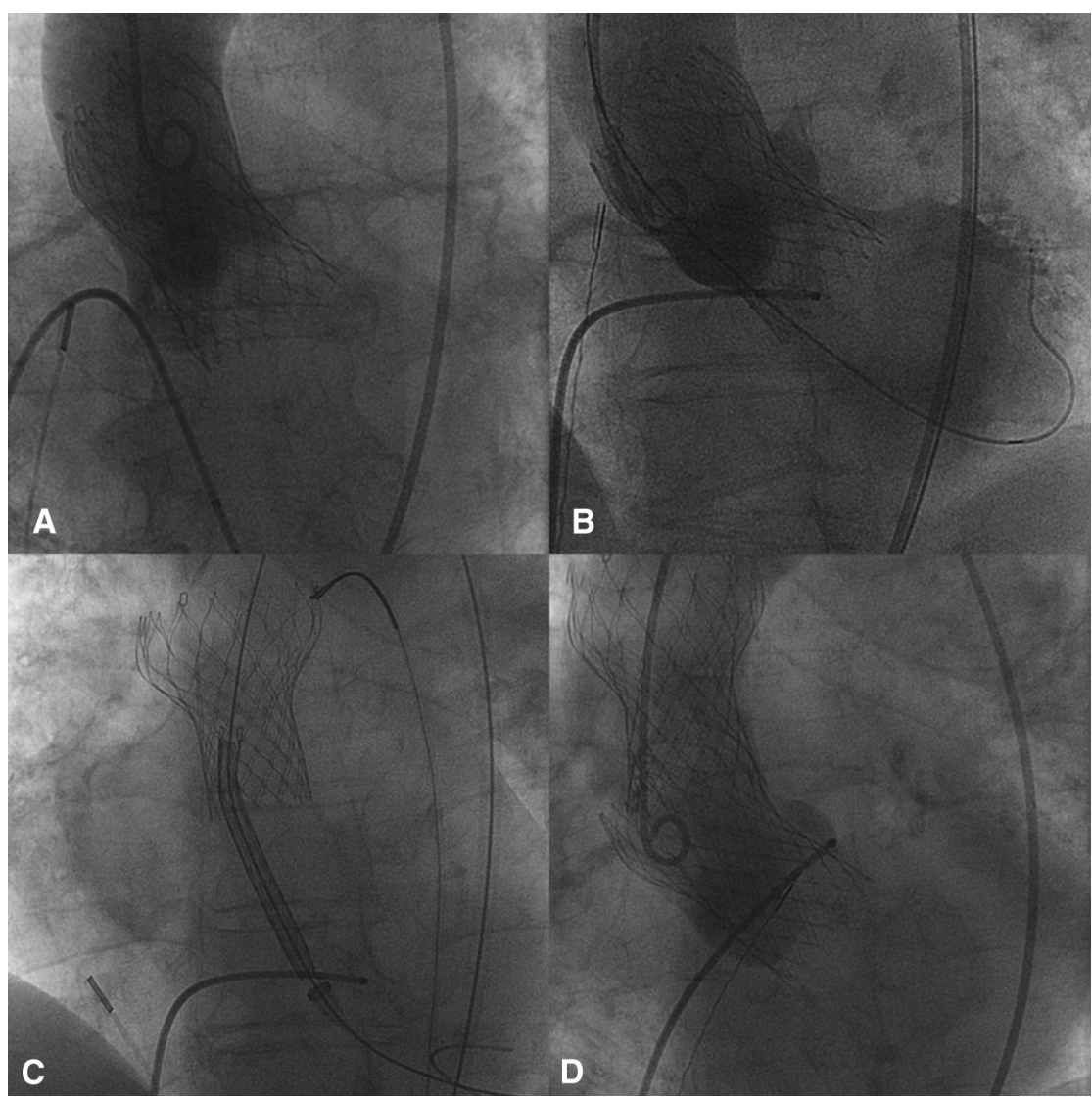

FIGURE 2. MCV31 implantation. A, Angiographic result after correct implantation of a 31-mm CoreValve, demonstrating mild paravalvular AR; B, CoreValve implanted too low with severe periprosthetic AR; C, introduction of a second prosthesis after spontaneous acute embolization of an MCV31 toward the ascending aorta; D, the result after CoreValve implantation in series.

preexisting poor left ventricular function, died of congestive heart failure induced by pneumonia, despite good valve prosthesis function. Another patient died of sequelae of delayed valve dislocation. On the sixth postprocedural day, the patient developed acute cardiac failure with respiratory insufficiency requiring intubation. Echocardiography revealed new severe $A R$, raising the suspicion of valve dislocation. On emergency angiography, downward displacement of the CoreValve toward the left ventricular outflow tract was diagnosed (Figure 3, $A-C$ ), which was subsequently treated with TAVin-TAV implantation of a smaller 29-mm CoreValve. Despite the successful procedure, the patient died of progressive coma probably caused by hypoxic cerebral damage. In 1 patient, the cause of death could not be established because death occurred after unsuccessful resuscitation (pulseless electrical activity) and no autopsy was performed. No additional 30-day mortality was reported.

In-hospital re-TAVI was performed in 2 patients. One patient underwent successful re-TAVI to address significant AR resulting from a too low implantation during the first procedure (as mentioned earlier). The other re-TAVI was performed in the case of delayed valve dislocation described earlier.
There were 2 cases of in-hospital stroke (4.2\%), both ischemic events. Of the 36 patients without previous pacemaker implantation, $15(41.7 \%)$ received a new pacemaker implantation after TAVI, mainly because of third-degree atrioventricular block $(\mathrm{n}=13)$. Other pacemaker indications were sick-sinus syndrome $(\mathrm{n}=1)$ and bradycardia in atrial fibrillation $(\mathrm{n}=1)$. Further data on in-hospital outcomes and echocardiographic results are outlined in Table 4.

\section{Device Success}

Device success was achieved in 31 patients $(66.0 \%)$. Reasons for not fulfilling the device success criteria were moderate or severe prosthetic AR in 3 patients $(6.4 \%)$; second valve implantation in 10 patients $(21.2 \%), 1$ of whom died in hospital; and in-hospital mortality in an additional 3 patients $(6.4 \%)$.

\section{Univariate Analysis}

A composite end point for malpositioning (suboptimal placement of the valve) was created for use in univariate analysis, including too low implantations requiring second valve implantation or snare catheter repositioning, and 
TABLE 3. Procedural data

\begin{tabular}{lc}
\hline & $\begin{array}{c}\text { Number }(\%) \\
(\mathbf{N}=\mathbf{4 7})^{*}\end{array}$ \\
\hline Approach & \\
$\quad$ Transfemoral & $36(76.6)$ \\
Direct aortic & $6(12.8)$ \\
$\quad$ Transaxillary & $5(10.6)$ \\
General anesthesia & $11(23.4)$ \\
Fluoroscopy time, minutes (median [interquartile range]) & $22.5[11]$ \\
Predilatation & $31(66.0)$ \\
Predilatation balloon size, mm & $24.6 \pm 1.8$ \\
Use of stabilizing ventricular pacing & $22(46.8)$ \\
Requirement of postdilatation & $15(31.9)$ \\
Snare catheter repositioning & $1(2.1)$ \\
Conversion to surgery & 0 \\
Use of extracorporeal circulation & 0 \\
Acute procedural success $\dagger$ & $36(76.6)$ \\
$\quad$ Second valve implanted & $8(17.0)$ \\
$\quad$ Aortic regurgitation grade 2 or higher & $2(4.3)$ \\
Intraprocedural death & $1(2.1)$ \\
\hline *Results are given as the number $(\%)$ except where indicated otherwise. $\dagger$ Successful \\
implantation of a single valve with proper functioning (correct anatomic position of \\
the valve with no moderate or severe AR present) and the patient leaving the operating \\
room alive.
\end{tabular}

acute and delayed valve dislocations. None of the variables analyzed showed a statistically significant association with the end point (Table 5). However, predilatation was nonsignificantly more often performed in patients free of

TABLE 4. Outcome and predischarge echocardiographic data

\begin{tabular}{|c|c|}
\hline & $\begin{array}{c}\text { Number }(\%) \\
(\mathbf{N}=\mathbf{4 7}) \%\end{array}$ \\
\hline \multicolumn{2}{|l|}{ In-hospital outcome } \\
\hline Mortality & $4(8.5)$ \\
\hline Stroke & $2(4.3)$ \\
\hline Myocardial infarction & 0 \\
\hline Bleeding & $4(8.6)$ \\
\hline Vascular complications & $2(4.3)$ \\
\hline New permanent pacemaker implantation & $15(41.7)$ \\
\hline Acute kidney injury (stage $\mathrm{I}) \dagger$ & $7(14.9)$ \\
\hline Delayed valve dislocation & $1(2.1)$ \\
\hline Re-TAVI & $2(4.3)$ \\
\hline $\begin{array}{l}\text { Length of hospital stay, days (median [interquartile } \\
\text { range]) }\end{array}$ & $6[3]$ \\
\hline Device success & $31(66.0)$ \\
\hline \multicolumn{2}{|l|}{ Postprocedural echocardiography $(\mathrm{N}=46)$} \\
\hline Left ventricular ejection fraction $<40 \%$ & $19(41.3)$ \\
\hline Peak aortic transvalvular pressure gradient, $\mathrm{mm} \mathrm{Hg}$ & $17.4 \pm 6.0$ \\
\hline Mean aortic transvalvular pressure gradient, $\mathrm{mm} \mathrm{Hg}$ & $9.6 \pm 3.8$ \\
\hline Aortic regurgitation grade 2 or higher & $7(14.9)$ \\
\hline Mitral valve regurgitation grade 2 or higher & $10(21.7)$ \\
\hline 30-d mortality $\ddagger$ & $4(8.5)$ \\
\hline
\end{tabular}

malpositioning, with a trend toward more aggressive predilatation (with bigger balloons) in this patient group.

\section{DISCUSSION}

This multicenter registry is the first to publish on clinical experiences with the MCV31 prosthesis for transcatheter treatment of severe aortic valve disease in patients with a large aortic valve annulus $(>27 \mathrm{~mm})$. In this registry, these patients could be further characterized by male gender and depressed left ventricular function, which is in line with recent insights on left ventricular dysfunction being an independent predictor of a large annulus. ${ }^{12}$ This situation stresses the importance of the availability of a large-valve prosthesis, as sufficient oversizing must be provided to decrease the amount of paravalvular AR in this vulnerable patient category. ${ }^{13}$ The MCV31 certainly fills a clinical need; this registry shows that this larger valve is indicated in up to $12 \%$ of patients suitable for TAVI. In the following paragraphs, the feasibility, efficacy, and safety of the MCV31 are discussed.

\section{Feasibility}

Over the years, transcatheter implantation of the Medtronic CoreValve has been performed with increasing success, reflecting evolving delivery techniques and operator experience. ${ }^{8}$ Several large registries have reported excellent procedural success rates for third-generation $26-\mathrm{mm}$ and 29-mm CoreValve implantations, reaching nearly $98 \% .^{14,15}$ The results for MCV31 implantations reported in this study are at odds with this trend, as the need for second valve implantations had a major impact on the acute procedural success rate. The incidence of second CoreValve implantation was high $(17.0 \%)$ compared with those reported in the real-world FRANCE2 and Sentinel registries $\left(3.5 \%\right.$ and $2.6 \%$, respectively) ${ }^{14,16}$ Second valve implantation was predominantly due to cases of too low first valve implantation, known to be the most common type of suboptimal CoreValve deployment causing significant paravalvular AR. ${ }^{17}$ Too low implantation of the prosthesis may lead to severe periprosthetic leakage, by leaving a gap between the aortic annulus plane and the pericardial skirt covering the prosthesis stent frame. TAV-in-TAV implantation is an established technique to address the problem of a low implant; snare catheter repositioning may be considered in some cases. ${ }^{17}$ Device success, as defined by VARC-2, decreased further in this registry as 1 case of delayed valve dislocation was observed, requiring re-TAVI. No previous reports on delayed dislocation after CoreValve implantation could be found. CoreValve dislocation is exclusively reported in the acute setting, occurring as valve embolization toward the ascending aorta, immediately after implantation or during snaring maneuvers. ${ }^{18,19}$ 


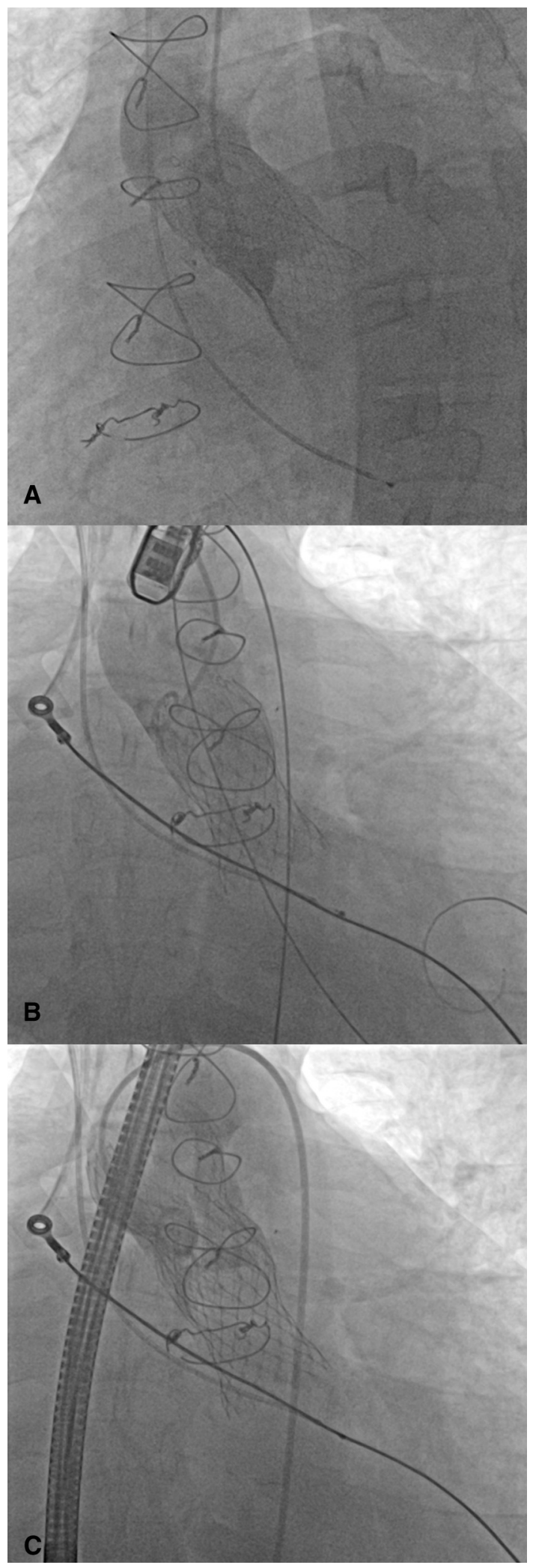

FIGURE 3. Delayed valve dislocation. A, Initial MCV 31 implanted a little low. B, Angiography in the same patient 6 days later; the MCV31 was dislocated toward the left ventricle. $\mathrm{C}$, Angiographic result after a TAV-in-TAV procedure.
TABLE 5. Univariate analysis

\begin{tabular}{|c|c|c|c|}
\hline Variable & $\begin{array}{c}\text { No malpositioning, } \\
\text { n }(\%)(\mathbf{N}=\mathbf{3 5})^{*}\end{array}$ & $\begin{array}{l}\text { Malpositioning, } \\
\text { n }(\%)(\mathbf{N}=11) \\
\end{array}$ & $\begin{array}{c}P \\
\text { value } \\
\end{array}$ \\
\hline \multicolumn{4}{|l|}{$\begin{array}{l}\text { Predictors for } \\
\text { malpositioning }\end{array}$} \\
\hline $\begin{array}{l}\text { Preprocedural } \\
\text { LVEF, \% }\end{array}$ & $45.8 \pm 14.3$ & $37.9 \pm 15.8$ & .11 \\
\hline $\begin{array}{l}\text { Preprocedural grade } \\
\text { AR, median } \\
\text { [interquartile range] }\end{array}$ & $1.0[1.0]$ & $1.0[2.0]$ & .57 \\
\hline $\begin{array}{c}\text { Average annulus } \\
\text { diameter, } \mathrm{mm}\end{array}$ & $27.2 \pm 1.6$ & $27.5 \pm 1.6$ & .66 \\
\hline Aortic annulus $>29 \mathrm{~mm}$ & $1(2.8)$ & $1(9.1)$ & .42 \\
\hline $\begin{array}{r}\text { Percentage of } \\
\text { oversizing } \dagger\end{array}$ & $12.5 \pm 4.7$ & $11.2 \pm 5.0$ & .34 \\
\hline Annulus eccentricity $\ddagger$ & $0.17 \pm 0.09$ & $0.13 \pm 0.09$ & .15 \\
\hline Transfemoral approach & $26(74.3)$ & $9(81.8)$ & 1.00 \\
\hline Predilatation & $25(71.4)$ & $5(45.5)$ & .15 \\
\hline $\begin{array}{l}\text { Balloon size, mm } \\
\quad \text { (median } \\
\text { [interquartile } \\
\text { range]) }\end{array}$ & $25.0[2]$ & $23.0[3]$ & .14 \\
\hline $\begin{array}{l}\text { Balloon to annulus } \\
\text { ratio } \oint\end{array}$ & $0.92 \pm 0.08$ & $0.89 \pm 0.05$ & .45 \\
\hline $\begin{array}{l}\text { Stabilizing ventricular } \\
\text { pacing }\end{array}$ & $16(47.1)$ & $5(45.5)$ & .92 \\
\hline \multicolumn{4}{|l|}{ Effect on outcome } \\
\hline $\begin{array}{l}\text { Fluoroscopy time, } \\
\text { minutes (median } \\
\text { [interquartile range]) }\end{array}$ & $21[12]$ & $27[15]$ & .07 \\
\hline Mortality & $2(5.7)$ & $1(9.1)$ & 1.00 \\
\hline Stroke & $1(2.8)$ & $1(9.1)$ & .42 \\
\hline $\begin{array}{l}\text { New permanent } \\
\text { pacemaker } \\
\text { implantation } \|\end{array}$ & $11(39.3)$ & $2(20.0)$ & .44 \\
\hline Acute kidney injury & $4(11.1)$ & $3(27.3)$ & .33 \\
\hline $\begin{array}{l}\text { Length of hospital stay, } \\
\text { days (median } \\
\text { [interquartile range]) }\end{array}$ & $6[3]$ & 7 [9] & .13 \\
\hline \multicolumn{4}{|c|}{$\begin{array}{l}L V E F, \text { Left ventricular ejection fraction; } A R, \text { aortic regurgitation. *Excluding the pa- } \\
\text { tient who had aortic dissection and died before valve implantation. †Calculated using } \\
\text { the formula ([prosthesis diameter }- \text { average diameter]/prosthesis diameter) } \times 100 \text {. } \\
\ddagger \text { Calculated using the formula } 1-(\text { minimal diameter/maximal diameter), where } \\
0 \text { indicates the annulus is a perfect circle. } \S \text { Ratio of the balloon diameter and aortic } \\
\text { annulus average diameter; increases as the balloon gets more oversized. } \| \text { Excluding } \\
\text { patients with previous pacemaker implantation. }\end{array}$} \\
\hline
\end{tabular}

All cases of malpositioning encountered in this registry involved a too low position of the MCV31, occurring either acutely (initial too low implantation) or in a later phase (delayed dislocation toward the left ventricle). This finding may indicate an operator tendency for too low valve positioning, although local experience with other CoreValve sizes is not supportive. Otherwise, it may reflect an intrinsic property of the MCV31 to creep into the left ventricle during deployment and maybe even during the following days, as stent frame expansion continues. Prosthesis design may contribute to this phenomenon, as the pronounced tapering 
of the stent frame inflow portion (producing an increasingly acute angle $\alpha$, absent in the smaller CoreValves) may act like an expandable dowel during expansion, pulling the prosthesis deeper into the left ventricular outflow tract (Figure 1). Because only the most distal part of the inflow portion has a diameter of $31 \mathrm{~mm}$, the valve should be implanted higher in the annulus than the smaller diameter valves.

The decision to incorporate too low implantation as well as valve dislocation in a composite malpositioning end point was based on the assumption that both complications may share suboptimal valve positioning as an underlying mechanism (although valve implantation height was not quantified). None of the variables used in the univariate analysis was significantly related to this end point. However, predilatation was more frequently applied in patients free of the composite malpositioning end point, with a modest trend toward more aggressive predilatation with larger balloons and a larger balloon to annulus ratio. Depressed left ventricular function may have been an important argument for omitting predilatation in patients in the malpositioning group, because impaired left ventricular function may be more sensitive to rapid pacing during predilatation. Predilatation has been considered a mandatory step in TAVI for some time, because it fractures valve calcifications and increases the effective orifice area, thereby facilitating an even deployment of the valve prosthesis. This concept is not supported by the literature, however; a feasibility study prospectively omitting predilatation in CoreValve procedures reported excellent results with achievement of technical success in $96.7 \%$ of 60 patients. $^{20}$ Multivariate analysis on predictors of malpositioning was not performed as the sample size was too small to generate robust data.

\section{Efficacy}

Postimplantation valve hemodynamics were good, considering the substantial significant decrease in both mean and peak transaortic gradients. None of the patients had residual stenosis on predischarge TTE. The incidence and distribution of paravalvular AR were satisfactory, although postdilatation, snaring and/or second valve implantation were indicated in half of the cases. The second valve implantations in this study were highly efficacious for resolving severe paravalvular AR in case of too low implantations, reducing the severity of AR to mild in 7 of 8 patients. The durability and long-term safety of TAV-in-TAV procedures is yet to be established, but previously published 1 -year outcomes are promising. ${ }^{17}$

Overall, moderate AR was present in $14.9 \%$ of patients on discharge, an incidence well within the range reported in a meta-analysis of SAPIEN and CoreValve devices. ${ }^{21}$ The incidence of moderate AR found in this study can be considered increased, however, as compared with the recently published results of the Sentinel registry, reporting postprocedural moderate AR in $9.9 \%$ of patients treated with the CoreValve throughout 2011 and $2012 .{ }^{16}$

\section{Safety}

The rate of in-hospital death was $8.5 \%$ in this registry, which can be regarded as high, as was the $4.2 \%$ incidence of stroke. Delayed valve dislocation seemed to be a harmful complication, as 1 death was clearly related to the sequelae of this event. The sole case of intraprocedural mortality in this registry was caused by aortic dissection, a rare and dreadful complication often leading to death. Aortic dissection occurred after failed attempts to cross the native valve with the delivery catheter before prosthesis deployment, and therefore cannot be attributed to the MCV31 device.

The absence of myocardial infarction in this study was not surprising, as reduced MCV31 height may decrease the already uncommon occurrence of this complication. The rate of new permanent pacemaker implantation was at the high end of the range usually observed after CoreValve implantation. ${ }^{16,22}$ This may indicate a trend for lower device implantation in this cohort, as low placement is associated with conduction disorders after CoreValve procedures. ${ }^{23}$ Alternatively, it may be conceivable that the tapered design of the valve inflow portion leads to a more localized exertion of radial pressure to the subvalvular structures during deployment, thereby increasing the likelihood of damaging the conduction system. In contrast to previous data, the incidence of pacemaker implantation was not related to too low first valve placement requiring TAV-in-TAV implantation. ${ }^{17}$

No clear unfavorable effect of the MCV31 on mitral valve function could be discerned, although a benefit on MR as seen after implantation of the Edwards SAPIEN valve was absent. ${ }^{24}$ Despite increased potential for complications, acutely performed TAV-in-TAV procedures seemed to be safe in this cohort, because no additional morbidity or mortality was observed. Only a nonsignificant higher rate of stage 1 acute kidney injury was noted, probably caused by the exposure to higher volumes of contrast fluids.

\section{Limitations}

The present study is an observational, retrospective, multicenter, single-arm registry and therefore subject to all the shortcomings involved in retrospective research. MSCT and echocardiography images were not evaluated by a core laboratory, which may have led to heterogeneity in valve sizing and assessment of paravalvular AR. Because of the sample size and observational retrospective nature of the study, no firm conclusions can be drawn on the underlying cause of the low procedural success rates in this registry. The absence of a control group consisting of patients treated with smaller CoreValve sizes leaves uncertainty about whether the results are operator, patient, or prosthesis 
dependent. No standard technique has been adopted for MCV31 implantation in this cohort; for example, no mandatory predilatation with prespecified balloon size or use of pacing during implantation was required. Furthermore, this registry is focused on procedural and inhospital outcomes and offers no insights into mid-term and long-term safety and efficacy. Larger series of MCV31 implantations with longer duration of follow-up, preferably matched to a cohort of smaller CoreValves, are necessary for thorough evaluation of this prosthesis.

\section{CONCLUSIONS}

In this retrospective multicenter registry, transcatheter treatment of severe AS with the MCV31 device seemed to be challenging, even in experienced hands. The valve should be implanted higher in the annulus than the smaller (26 and $29 \mathrm{~mm}$ ) CoreValves, because only the short inflow portion of the valve has a diameter of $31 \mathrm{~mm}$. Device success was low, predominantly because of malpositioning requiring second valve implantation. The rate of new pacemaker implantations after the procedure was high. If the MCV31 is properly implanted, it offers adequate valve hemodynamics and proper functioning.

The authors would like to thank Wiebren Herder and Alessandro Sticchi for their efforts in data collection.

\section{References}

1. Leon MB, Smith CR, Mack M, Miller DC, Moses JW, Svensson LG, et al. Transcatheter aortic-valve implantation for aortic stenosis in patients who cannot undergo surgery. N Engl J Med. 2010;363:1597-607.

2. Reynolds MR, Magnuson EA, Lei Y, Leon MB, Smith CR, Svensson LG, et al. Health-related quality of life after transcatheter aortic valve replacement in inoperable patients with severe aortic stenosis. Circulation. 2011;124:1964-72.

3. Holmes DR Jr, Mack MJ, Kaul S, Agnihotri A, Alexander KP, Bailey SR, et al. 2012 ACCF/AATS/SCAI/STS expert consensus document on transcatheter aortic valve replacement. J Am Coll Cardiol. 2012;59:1200-54.

4. Genereux P, Head SJ, Wood DA, Kodali SK, Williams MR, Paradis JM, et al. Transcatheter aortic valve implantation 10-year anniversary: review of current evidence and clinical implications. Eur Heart J. 2012;33:2388-400.

5. John D, Hausen S, Latsios G, Yuecel S, Eberle HC, Farazandeh M, et al. Numerous patients fail the aortic annulus criteria in transcatheter aortic valve implantation - comparison of current devices. Poster presented at the 23rd Annual Symposium of the Transcatheter Cardiovascular Therapeutics, November 7, 2011; San Franscisco, Calif.

6. Cilingiroglu M, Hakeem A. Fate of mitral regurgitation following transcatheter aortic valve implantation. Catheter Cardiovasc Interv. 2011;78:645-6.

7. Bleiziffer S, Ruge H, Horer J, Hutter A, Geisbusch S, Brockmann G, et al. Predictors for new-onset complete heart block after transcatheter aortic valve implantation. JACC Cardiovasc Interv. 2010;3:524-30.
8. Grube E, Buellesfeld L, Mueller R, Sauren B, Zickmann B, Nair D, et al. Progress and current status of percutaneous aortic valve replacement: results of three device generations of the CoreValve Revalving system. Circ Cardiovasc Interv. 2008; $1: 167-75$.

9. Bruschi G, De Marco F, Fratto P, Oreglia J, Colombo P, Paino R, et al. Direct aortic access through right minithoracotomy for implantation of self-expanding aortic bioprosthetic valves. J Thorac Cardiovasc Surg. 2010;140:715-7.

10. Petronio AS, De Carlo M, Bedogni F, Marzocchi A, Klugmann S, Maisano F, et al. Safety and efficacy of the subclavian approach for transcatheter aortic valve implantation with the CoreValve revalving system. Circ Cardiovasc Interv. 2010; 3:359-66.

11. Kappetein AP, Head SJ, Genereux P, Piazza N, van Mieghem NM, Blackstone EH, et al. Updated standardized endpoint definitions for transcatheter aortic valve implantation: the Valve Academic Research Consortium-2 consensus document. J Am Coll Cardiol. 2012;60:1438-54.

12. Ng ACT, Yiu KH, Ewe SH, Van Der Kley F, Bertini M, De Weger A, et al. Influence of left ventricular geometry and function on aortic annular dimensions as assessed with multi-detector row computed tomography: Implications for transcatheter aortic valve implantation. Eur Heart J. 2011;32:2806-13.

13. Fraccaro C, Al-Lamee R, Tarantini G, Maisano F, Napodano M, Montorfano M, et al. Transcatheter aortic valve implantation in patients with severe left ventricular dysfunction: immediate and mid-term results, a multicenter study. Circ Cardiovasc Interv. 2012;5:253-60.

14. Gilard M, Eltchaninoff H, Iung B, Donzeau-Gouge P, Chevreul K, Fajadet J, et al Registry of transcatheter aortic-valve implantation in high-risk patients. $N$ Engl J Med. 2012;366:1705-15.

15. Tamburino C, Capodanno D, Ramondo A, Petronio AS, Ettori F, Santoro G, et al Incidence and predictors of early and late mortality after transcatheter aortic valve implantation in 663 patients with severe aortic stenosis. Circulation 2011;123:299-308

16. Di Mario C, Eltchaninoff H, Moat N, Goicolea J, Ussia GE, Kala P, et al. The 2011-12 pilot European Sentinel Registry of Transcatheter Aortic Valve Implantation: in-hospital results in 4,571 patients. EuroIntervention. 2013;8:1362-71.

17. Ussia GP, Barbanti M, Ramondo A, Petronio AS, Ettori F, Santoro G, et al. The valve-in-valve technique for treatment of aortic bioprosthesis malposition an analysis of incidence and 1-year clinical outcomes from the italian CoreValve registry. J Am Coll Cardiol. 2011;57:1062-8.

18. Ussia GP, Barbanti M, Sarkar K, Aruta P, Scarabelli M, Cammalleri V, et al Transcatheter aortic bioprosthesis dislocation: technical aspects and midterm follow-up. EuroIntervention. 2012;7:1285-92.

19. Geisbusch S, Bleiziffer S, Mazzitelli D, Ruge H, Bauernschmitt R, Lange R. Inci dence and management of corevalve dislocation during transcatheter aortic valve implantation. Circ Cardiovasc Interv. 2010;3:531-6.

20. Grube E, Naber C, Abizaid A, Sousa E, Mendiz O, Lemos P, et al. Feasibility of transcatheter aortic valve implantation without balloon pre-dilation: a pilot study. JACC Cardiovasc Interv. 2011;4:751-7.

21. Lerakis S, Hayek SS, Douglas PS. Paravalvular aortic leak after transcatheter aortic valve replacement: current knowledge. Circulation. 2013;127:397-407.

22. Khatri PJ, Webb JG, Rodes-Cabau J, Fremes SE, Ruel M, Lau K, et al. Adverse effects associated with transcatheter aortic valve implantation: a meta-analysis of contemporary studies. Ann Intern Med. 2013;158:35-46.

23. Piazza N, Onuma Y, Jesserun E, Kint PP, Maugenest AM, Anderson RH, et al Early and persistent intraventricular conduction abnormalities and requirements for pacemaking after percutaneous replacement of the aortic valve. JACC Cardiovasc Interv. 2008;1:310-6.

24. Samim M, Stella PR, Agostoni P, Kluin J, Ramjankhan F, Sieswerda G, et al Transcatheter aortic implantation of the Edwards-SAPIEN bioprosthesis: insights on early benefit of TAVI on mitral regurgitation. Int J Cardiol. 2011; 152:124-6. 


\section{SUPPLEMENTARY METHODS}

This supplementary methods section provides additional information on the methodology used in the 31-mm Medtronic CoreValve (MCV31) registry, discussing patient work-up, device characteristics, transcatheter implantation procedures, and statistical analysis.

\section{Study Design}

The study is an observational retrospective multicenter single-arm registry. All patients who underwent TAVI for severe aortic valve disease using the MCV31 device were retrospectively identified. Patients selected for TAVI had been considered unsuitable for SAVR by consensus of a cardiologist and cardiac surgeon, either because of a high predicted operative mortality risk (logistic EuroSCORE >15) or the presence of absolute contraindications for SAVR (eg, porcelain aorta). Further details on patient selection have been published previously. ${ }^{\mathrm{E} 1}$

Pre-, intra-, and postprocedural data were retrospectively collected and documented in a registry. All patients gave informed consent for the procedure and because of the retrospective nature of the study design, ethics committee approval was waived.

\section{Patient Evaluation}

The evaluation of eligibility for TAVI included transthoracic echocardiography (TTE), transesophageal echocardiography (TEE), coronary angiography, and thoracoabdominal multislice computed tomography (MSCT). TTE was performed in all patients before TAVI and after the procedure before discharge. Left ventricular, valvular, and prosthesis function were evaluated by local experienced echocardiographers in compliance with dedicated guidelines. ${ }^{\mathrm{E} 2 \mathrm{E} 3}$ TEE could be also be performed, according to the routine of each participating center, to analyze concomitant mitral valve disease and measure the aortic annulus diameter. MSCT imaging was used to assess the suitability of vascular entrance sites, as well as to determine aortic annulus dimensions.

Prosthesis sizing was based on MSCT-derived aortic annulus measurements in most patients; in some cases, only TEE measurements were available. The reliability of these particular measurements and their compliance with findings from other imaging modalities were considered with close scrutiny by the interventional teams.

\section{Device}

The MCV31 device received CE (Conformité Européenne) approval in August 2011 for transfemoral, transaxillary and direct aortic implantation. It is currently the only valve prosthesis available for transcatheter treatment of patients with an aortic annulus diameter greater than $27 \mathrm{~mm}$. The MCV31 has roughly the same design characteristic design as its smaller 26-mm and 29-mm predecessors. ${ }^{\mathrm{E} 4}$ It consists of a trileaflet porcine pericardial valve sutured into a nitinol frame. The frame has diamondshaped cells with an hourglass-like architecture, in which 3 distinct regions of radial force can be identified. The outflow portion has low radial force and is designed to stabilize and center the device in the ascending aorta. The center portion contains the porcine leaflets and is therefore constrained to avoid obstruction of the coronary arteries. The inflow portion has high radial force to exclude the calcified leaflets and maintain intra-annular anchoring, and is covered with a pericardial skirt to minimize paravalvular aortic regurgitation (AR) after implantation. It is only this inflow portion that is actually larger in the 31-mm prosthesis compared with the $29-\mathrm{mm}$ prosthesis (see article Figure 1), giving rise to a pronounced tapering of the inflow portion. Therefore, correct placement, high enough to allow proper apposition of the enlarged inflow part to the native aortic valve, is more critical than with the smaller sizes. The MCV31 is deployed using an 18-French delivery catheter with an AccuTrak stability layer (Medtronic Inc, Minneapolis, Minn).

\section{TAVI}

The TAVI procedures were performed via a transfemoral, transaxillary, or direct aortic approach according to the choice of the operators, using standard access techniques, under general anesthesia or conscious sedation. Technical details of the applied approaches have been discussed in detail elsewhere. $^{\mathrm{E} 5, \mathrm{E} 6}$

Predilatation of the native aortic valve was left to operator discretion and preferably performed to facilitate prosthesis implantation. Motivations for omitting predilatation were poor left ventricular function and mixed disease with an important regurgitation component. Prosthesis deployment was performed under fluoroscopic guidance. The use of stabilizing ventricular pacing (100-120 beats per minute) during deployment was at the discretion of the operator.

After implantation, aortography was used to assess valvular location and function as well as patency of the left and right coronary ostia. Valvular function was thereafter examined by echocardiography (either TTE, TEE, or intracardiac echocardiography), before the patient left the operating room.

\section{End Point Definitions}

In-hospital complications were registered in concordance with the recently published Valve Academic Research Consortium-2 (VARC-2) consensus document. ${ }^{\mathrm{E7}}$ In compliance with the VARC-2 definitions, device success was defined as the proper implantation of the first valve prosthesis used, with intended performance of the prosthetic heart valve (peak aortic flow velocity $<3 \mathrm{~m} / \mathrm{s}$ and no moderate or severe $\mathrm{AR}$ ) and no procedural mortality (30-day all-cause mortality). ${ }^{\mathrm{E7}}$ In addition, acute procedural success was defined by the authors as the successful implantation of a single valve with proper functioning (correct anatomic position of the valve with no moderate or severe AR present) and the patient leaving the operating room alive.

\section{Statistical Analysis}

All data were analyzed using IBM SPSS Statistics software version 20 (IBM Corp., Armonk, NY). Results for continuous variables were presented as means \pm standard deviation or medians [interquartile range], as considered appropriate. Categorical variables were reported as counts and percentages. Comparison of continuous variables was done using the Student $t$ test for unpaired measures or the paired $t$ test for repeated measures or their nonparametric equivalents, the Mann-Whitney $U$ test and Wilcoxon signed ranks test, where appropriate. Categorical variables were analyzed using the $\chi^{2}$ or Fisher exact test.

\section{E-References}

E1. Holmes DR Jr, Mack MJ, Kaul S, Agnihotri A, Alexander KP, Bailey SR, et al. $2012 \mathrm{ACCF} / \mathrm{AATS} / \mathrm{SCAI} / \mathrm{STS}$ expert consensus document on transcatheter aortic valve replacement. J Am Coll Cardiol. 2012;59:1200-54.

E2. Baumgartner H, Hung J, Bermejo J, Chambers JB, Evangelista A, Griffin BP, et al. Echocardiographic assessment of valve stenosis: EAE/ASE recommendations for clinical practice. Eur J Echocardiogr. 2009;10:1-25.

E3. Kappetein AP, Head SJ, Genereux P, Piazza N, van Mieghem NM, Blackstone EH, et al. Updated standardized endpoint definitions for transcatheter aortic valve implantation: the Valve Academic Research Consortium-2 consensus document. J Am Coll Cardiol. 2012;60:1438-54.

E4. Grube E, Buellesfeld L, Mueller R, Sauren B, Zickmann B, Nair D, et al. Progress and current status of percutaneous aortic valve replacement: results of three device generations of the CoreValve Revalving system. Circ Cardiovasc Interv. 2008; 1:167-75.

E5. Bruschi G, De Marco F, Fratto P, Oreglia J, Colombo P, Paino R, et al. Direct aortic access through right minithoracotomy for implantation of self-expanding aortic bioprosthetic valves. J Thorac Cardiovasc Surg. 2010;140:715-7.

E6. Petronio AS, De Carlo M, Bedogni F, Marzocchi A, Klugmann S, Maisano F, et al. Safety and efficacy of the subclavian approach for transcatheter aortic valve implantation with the CoreValve revalving system. Circ Cardiovasc Interv. 2010; 3:359-66. 